Paul Woodfield ${ }^{1,2} /$ Christine Woods $^{2}$ / Deborah Shepherd ${ }^{2}$

\title{
Appreciating Entrepreneurship: A New Approach for Field Research
}

\author{
${ }^{1}$ Department of Management, Auckland University of Technology, Auckland, New Zealand, E-mail: paul.woodfield@aut.ac.nz \\ ${ }^{2}$ Department of Management and International Business, University of Auckland Business School, Auckland, New Zealand, \\ E-mail: paul.woodfield@aut.ac.nz
}

\begin{abstract}
:
The purpose of this paper is to explore the advantages and disadvantages of utilizing an appreciative inquiry approach for entrepreneurship research within the family business context. We argue that there is an opportunity to shift the focus of family business studies from a "deficit oriented approach" toward adopting a positive organizational lens through"appreciative inquiry" principles. We review the background to appreciative inquiry including from its inception in the 1980s; the definitions, principles, models for appreciative inquiry; and the theoretical foundations of the appreciative inquiry approach. We will draw on examples from a recent study that applied appreciative inquiry principles to investigate what worked well in entrepreneurial family businesses. By exploring the generative characteristics, we are better placed to understand the strengths of a family firm. This leads to research that presents what works well, and can be built on in family businesses, rather than objectifying the problems to be solved. Our contribution lies in how, as a positive organizational lens, appreciative inquiry principles inform research in the entrepreneurial family business context. In practice, finding the advantages and disadvantages of using an appreciative protocol could lead to future studies adopting this lens, and possibly past studies being reinvigorated with a shift of focus.
\end{abstract}

Keywords: appreciative inquiry, constructionism, entrepreneurship research, family business, family entrepreneurship, positive organizational study

DOI: $10.1515 /$ erj-2016-0027

\section{Introduction}

"The way we see things is the source of the way we think and the way we act"- Stephen Covey

(The 7 Habits of Highly Effective People)

Recently there has been a call to embrace a positive organizational lens in family business research (Sharma, De Massis, and Gagne 2014; Ceja-Barba 2014). While there is a growing body of research using appreciative inquiry in the organizational change and development fields, with the exception of a small number of studies (e. g., Poza and Messer 2001; Miller et al. 2005), family business researchers have not engaged with this approach or adopted such a lens. This is also true for the existing body of entrepreneurship research. Herein lies the paradox. Entrepreneurship leans toward solving problems, reframing challenges, and using issues as a source of inspiration. However the conventional lens for studying entrepreneurship tends to observe the opposite. Is it possible that as entrepreneurship scholars we are not capturing the full essence of entrepreneurship with a deficit orientated critical lens? Are we not observing the somewhat obvious characteristics of entrepreneurship, that is, an appreciative outlook toward what can be?

Appreciative inquiry is considered an innovative, important, and significant paradigm shift in organization studies (Cady and Caster 2000; Reed 2007), and in addition to its practical application has also been demonstrated as a research tool (e. g., Michael 2005; Robinson et al. 2013). The focus of appreciative inquiry is on what works well in an organization, rather than the problems, challenges and issues (Cooperrider et al. 2000; Cooperrider and Srivestva 1987). The appreciative inquiry process aims to leave"deficit orientated approaches" behind, instead strengthening a systems approach to understanding organizations by asking questions that"apprehend, anticipate, and heighten positive potential" (Cooperrider, Whitney, and Stavros 2008 , 2-3) (Figure 1). 


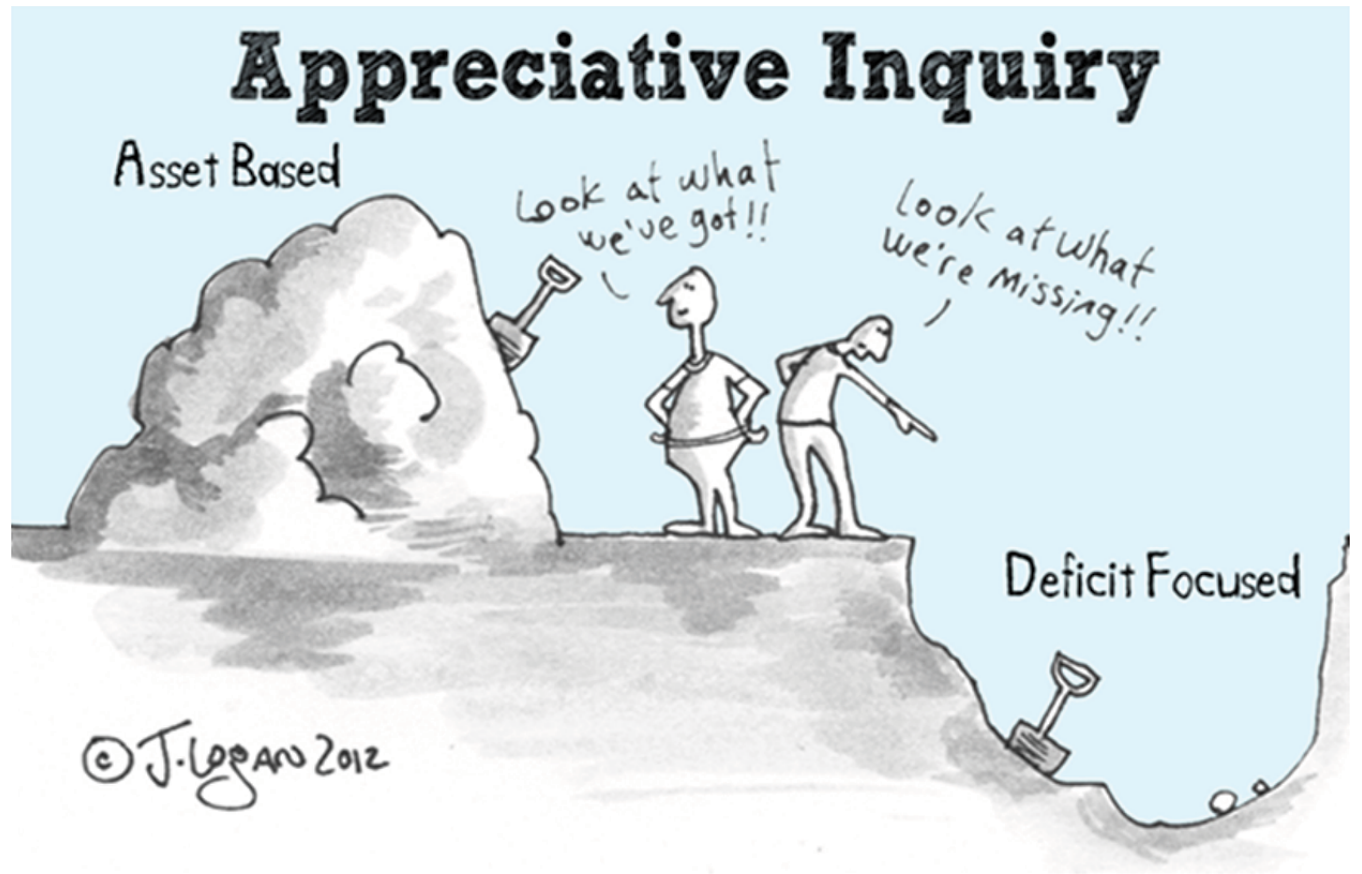

Figure 1: Appreciative inquiry- asset-based versus deficit focused (Logan 2016).

Appreciative inquiry is distinguished by its forward-thinking evaluation of organizations borrowed from the organization development field (Cooperrider and Srivestva 1987; Cooperrider and Sekerka 2006). An appreciative inquiry crafts the "unconditional positive question," and"focus(es) on the speed of imagination and innovation-instead of the negative, critical, and spiraling diagnoses" (Cooperrider, Whitney, and Stavros 2008 ,3). Appreciative inquiry research is an "exemplar of the integration of theory and practice" (Reed 2007,182 ). The assumption of an appreciative inquiry approach is that every organization has areas that work well and that change can be created in a positive way through this form of inquiry (Cooperrider, Whitney, and Stavros 2008).

In this article, we explore the implementation of appreciative inquiry principles in an entrepreneurship study within a family business setting. We highlight this potential through an examination of the appreciative inquiry approach, first by presenting the background and theoretical foundations of appreciative inquiry, then by reviewing criticisms of the approach. We present examples of how the approach was used in a recent study and explain what the potential value is in implementing appreciative inquiry methodology in entrepreneurship research. In doing so we engage in the recent call by Ceja-Barba (2014) and Sharma, De Massis, and Gagne (2014) to adopt a positive organizational lens and suggest there is significant potential in embracing an appreciative inquiry lens within entrepreneurship research.

\section{Appreciative Inquiry Background}

\section{Origin of Appreciative Inquiry}

The appreciative inquiry concept originated at Case Western Research University as part of a doctoral thesis conducted by David Cooperrider (1986). This was the first application of the appreciative inquiry approach, centered around the Cleveland Clinic- a highly esteemed healthcare organization- where Cooperrider gained permission to conduct a study that focused on positive factors. He discussed these positive factors with people in the organization and examined their responses through a positive framework. This approach was considered radical at the time because attention was paid to building positive ways in which to work, instead of concentrating on the immediate problems and trying to find ways of solving them (Reed 2007). In particular, Cooperrider was astonished at the "level of positive cooperation, innovation, and egalitarian governance when they were at their most effective" (Coghlan, Preskill, and Tzavaras Catsambas 2003, 7). This led him to take those data that were geared toward the strength of the organization and:

... systematically and deliberately"appreciate" everything of value, then use the positive analysis to speculate on the potentials and possibilities for the future... The results of the study created such a powerful 
positive stir that the board requested that this Appreciative Inquiry method be used at all levels of the 8,000-person organization to facilitate change.

(Cooperrider, Whitney, and Stavros 2003 , xxvii)

One of the outcomes of this study was the development of theory related to"the egalitarian organization" (Srivastva and Cooperrider 1986). However, it was Cooperrider's article“Appreciative inquiry in organizational life" co-authored with his mentor, Shuresh Srivestva, that outlined the appreciative inquiry process which underpinned a succession of articles articulating the appreciative inquiry concept in relation to what positive aspects give life to an organization (Cooperrider and Srivestva 1987). Later, appreciative inquiry became known as a significant innovation in action research (Bushe 1999). The concept became recognized as a tool for field research that reached beyond organizational development toward being utilized as a research methodology, though"appreciative inquiry as a research approach seems to be at a formative stage in development" (Reed 2007 , 201). Alongside appreciative inquiry, similar approaches included"Asset Based Community Development" (Mathie and Cunningham 2003), the"solutions focus" (Jackson and McKergow 2002), and"positive organizational scholarship" (Cameron, Dutton, and Quinn 2003; Dick 2004). These approaches- excluding positive organizational scholarship which considers appreciative inquiry an important organizational development approach (Caza and Cameron 2008)- can be found to integrate, or are compared with, appreciative inquiry. However these approaches tend to focus on the"elucidation and engagement of individual competencies, ignoring relational realities and for the most part doing little to transform the nature of organization itself" (Bushe 2011 ,93). Bushe (2011) makes the distinction that, necessary for generative momentum in the change process, appreciative inquiry not only focuses on existing strengths of an organization but also engages all stakeholders in the re-imagining process, and encourages ownership of what the organization is to become.

\section{Practical Foundation of Appreciative Inquiry}

Organizational development (OD) envelopes the behavior, culture and design aspects of a firm and promotes an increase in organization effectiveness and health (Beckhard 1969). OD is a response to change and a complex educational strategy (Bennis 1969). As a process of fundamental change (Burke 1997), it is typically a program that is planned organization-wide (Schein 1969), which engages top management and employees (French, Bell, and Zawacki 1989). As such, organizational development is a way to implement strategies that manage change through planned interventions and education experienced at all levels. The outcome is an effective, dynamic and strong environment that fosters the sustainability of the organization. Schein and Greiner (1977) state:

Organization development's action-emphasis similarly holds that bureaucratic organizations need to be "unfrozen" and moved toward an organic state characterized by a matrix structure (or at least by project teams) and by open communications, interdependence among groups, and expanded levels of trust, participation, joint problem solving, risk taking, and innovation within groups

(Schein and Greiner 1977,48 ).

Appreciative inquiries are typically conducted as action research studies1 and in consulting contexts (Egan and Lancaster 2005; Cooperrider et al. 2000; Yaeger, Sorensen, and Bengtsson 2005; Cooperrider, Whitney, and Stavros 2008; Cady and Caster 2000). These studies usually relate to strategic or micro-level applications such as strategic planning, culture change, or crafting a vision, but have also been used in leadership development, creating dialogue in an organization, and succession planning (Yaeger, Sorensen, and Bengtsson 2005). In their seminal article, Cooperrider and Srivastva (1987) devoted a section to the"reawakening the spirit of action research" for appreciative inquiry (p. 147). In this they argued that there was a"lack of generative theorizing in the literature" and that a"deficiency perspective" (that is a problem and challenge focused paradigm) prevailed which concentrated on a"visible but narrow realm of reality" (p. 153). The adoption of an action research methodology aimed to achieve a more consultative, ethnographic approach. At this juncture lies the potential to adapt the appreciative inquiry approach for entrepreneurship research. In particular, corporate entrepreneurship and family entrepreneurship are suitable organizational contexts where strategy, culture, and vision are embodied through entrepreneurship.

\section{Theoretical Foundations of Appreciative Inquiry}

Cooperrider was influenced by ideas presented in Ken Gergen's social research in the 1970s as well as Gareth Morgan's research that explored relationships among paradigms, metaphors, and puzzle solving in organiza- 
tions (Morgan 1980). Gergen argued that normal scientific assumptions did not capture human relationships effectively which spurred the creation of a social science concentrated on "generative capacity" (Gergen 1978).2

As such, appreciative inquiry is underpinned by constructionism 3 which has its foundations in the social sciences (Cooperrider and Srivestva 1987). Nordqvist, Hall, and Melin (2009) describe a constructionist approach as a negotiation of interpretations and representations through conversation where"interpretations are made both by the actors under study and by the researcher studying them" (Nordqvist, Hall, and Melin 2009 ,298). Miles and Huberman (1994) add that"researchers are no more'detached' from their objects of study than are their informants" (p. 8). Creswell (2009) echoed this, stating that the researcher and the subjects can"construct meaning in a given situation" (p.8). Crotty (1998) viewed constructionism as bringing together objectivity and subjectivity without promoting either as the one true or valid interpretation, and that it is flexible by nature with more concern for curiosity than being right. Crotty explained this notion in the following way:

All knowledge and therefore all meaningful reality as such, is contingent upon human practices, being constructed in and out of interaction between human beings and their world and transmitted within an essentially social context... meaning is not discovered but constructed.

$(1998,42-43)$

Cooperrider and Avital (2004), when describing the underpinnings of appreciative inquiry, captured constructionism as a philosophical paradigm shift that breaks down the barriers between the observer and those being observed, toward a more collegial, collaborative approach to making sense of an organization.

An approach to human science inquiry and practice that replaces the individual with the relationship as the locus of knowledge. Philosophically, constructionism involves a decisive shift in Western intellectual tradition from cogito ergo sum [I think, therefore I am] to communicamus ergo sum [we communicate, therefore I am].

\section{(Cooperrider and Avital 2004, xvii-xviii)}

Appreciative inquiry centers on five original principles which have developed over time to reflect new thinking and learning (Table 1). Largely these principles are derived from Cooperrider's original doctoral research and later labeled, synthesized, and described. These key tenets provide insight into the ongoing conceptualization of appreciative inquiry and link theoretical developments across a variety of disciplines, including human development, organizational, and learning theories (Reed 2007).

Table 1: Principles of appreciative inquiry (The Center for Appreciative Inquiry 2016).

\begin{tabular}{|c|c|c|c|}
\hline Principle & Description & Description & Source \\
\hline \multicolumn{4}{|c|}{ Original appreciative inquiry principles } \\
\hline $\begin{array}{l}\text { The Constructionist } \\
\text { Principle: }\end{array}$ & Words Create Worlds & $\begin{array}{l}\text { Reality, as we know it, is a } \\
\text { subjective vs. objective } \\
\text { state and is socially created } \\
\text { through language and } \\
\text { conversations. }\end{array}$ & $\begin{array}{l}\text { (Cooperrider, Whitney, and } \\
\text { Stavros 2003; 2008) }\end{array}$ \\
\hline The Simultaneity Principle: & Inquiry Creates Change & $\begin{array}{l}\text { Inquiry is an intervention. } \\
\text { The moment we ask a } \\
\text { question, we begin to } \\
\text { create a change."The } \\
\text { questions we ask are } \\
\text { fateful." }\end{array}$ & \\
\hline The Poetic Principle: & $\begin{array}{l}\text { We Can Choose What We } \\
\text { Study }\end{array}$ & $\begin{array}{l}\text { Teams and organizations, } \\
\text { like open books, are } \\
\text { endless sources of study } \\
\text { and learning. What we } \\
\text { choose to study makes a } \\
\text { difference. It describes- } \\
\text { even creates- the world as } \\
\text { we know it. }\end{array}$ & \\
\hline
\end{tabular}


The Anticipatory Principle: Image Inspires Action

The Positive Principle:

Positive Questions Lead to Positive Change

\section{Emergent appreciative inquiry principles \\ The Wholeness Principle: Wholeness Brings Out the Best}

The Enactment Principle:

Acting" As If" is Self-Fulfilling

The Free Choice Principle:

The Narrative Principle:

The Awareness Principle:
Stories are Transformative

Free Choice Liberates Power

Be Conscious of Underlying Assumptions.
Human systems move in the direction of their images of the future. The more positive and hopeful the image of the future, the more positive the present-day action. Momentum for [small or] large-scale change requires large amounts of positive affect and social bonding. This momentum is best generated through positive questions that amplify the positive core. ${ }^{1}$

Wholeness brings out the best in people and organizations. Bringing all stakeholders together in large group forums stimulates creativity and builds collective capacity. To really make a change, we must" be the change we want to see." Positive change occurs when the process used to create the change is a living model of the ideal future.

People perform better and are more committed when they have the freedom to choose how and what they contribute. Free choice stimulates organizational excellence and positive change. ${ }^{2}$

We construct stories about our lives (personal and professional) and live into them. ${ }^{3}$

Understanding and being aware of our underlying assumptions are important to developing and cultivating good relationships. Practicing cycles of action and reflection can build one's self-awareness. ${ }^{4}$
(Cooperrider, Whitney, and Stavros 2003; 2008)

(Barrett and Fry 2005)

(Stavros and Torres 2005) 
Table 2 represents the differences and basic assumptions between problem solving and appreciative inquiry. The comparison illuminates some interesting traits on the appreciative inquiry side that strongly align with entrepreneurial attributes or characteristics.

Table 2: Two paradigms for organizational change (Cooperrider, Whitney, and Stavros 2008,8 ).

\begin{tabular}{ll}
\hline Paradigm 1: Problem solving & Paradigm 2: Appreciative inquiry \\
\hline Felt need- Identification of problems & Appreciating- Valuing the best of what is \\
Analysis of causes & Envisioning-What might be \\
Analysis of possible Solutions & Dialoguing-What should be \\
Action planning (Treatment) & Innovating- What will be \\
Basic Assumption: & Basic assumption: \\
Organizing is a problem to be solved & Organizing is a mystery (infinite capacity) to be embraced \\
\hline
\end{tabular}

By way of example, one prominent entrepreneurship definition operationalized in entrepreneurship education is:

Entrepreneurship is a dynamic process of vision, change, and creation. It requires an application of energy and passion towards the creation and implementation of new ideas and creative solutions. Essential ingredients include the willingness to take calculated risks-in terms of time, equity, or career; the ability to formulate an effective venture team; the creative skill to marshall needed resources; and fundamental skill of building solid business plan; and finally, the vision to recognize opportunity where others see chaos, contradiction, and confusion.

(Kuratko 2005 , 578)

This definition displays elements of the appreciative inquiry paradigm including the basic assumption that"organization is a mystery" (Table 2) which can be likened to the "chaos, contradiction, and confusion" (Kuratko 2005,578 ) entrepreneurs face in recognizing opportunities. Core tenets of entrepreneurship definitions are vision and innovation which are features of entrepreneurial leadership, that is"... the entrepreneur's ability to anticipate, envision, maintain flexibility, think strategically, and work with others to initiate changes that will create a viable future for the organization" (Kuratko and Audretsch 2009 , 7). As outlined earlier, it is possible that as entrepreneurship scholars we are not capturing the full essence of entrepreneurship through a deficit orientated critical lens. Instead, we could be missing some of the richness and diversity of perspective that entrepreneurship offers.

\section{Criticisms of Appreciative Inquiry}

There have been a number of critiques of appreciative inquiry; most of them related to the process conducted through appreciative inquiry consulting. Bushe (2012) described three waves of criticism. The first wave came from organization development researchers who were steeped in the tradition of identifying dysfunction in organizations and took exception to an approach that solely focused on what works well. These critiques were often from a positivistic mindset (e. g. Golembiewski 1998), not accounting for the social constructionist's view where"research only makes sense within a community of discourse... and constructs the world it studies" (Bushe 2012 , 14). This distinction shifts the reasoning from asking whether a method generates valid information, toward a view of "whose interests does it serve and is it generative in the service of those interests?" (Bushe 2012 , 14). Bushe moves on to describe the second wave of critique as grounded in social constructionism however these assessments were ill informed and had a superficial understanding of appreciative inquiry (e. g. Fineman 2006; Grant and Humphries 2006). For example, Bushe $(2012,14)$ surmises Fineman's article as not recognizing"advocates of appreciative inquiry are just as suspicious as critical theorists". Finally, the third wave included scholars that were sympathetic toward appreciative inquiry but cautious about just focusing on positive experiences and not allowing meaningful conversations about resentments to occur (e. g. Egan and Lancaster 2005; Fitzgerald, Oliver, and Hoxsey 2010). Egan and Lancaster (2005) referred to difficult interpersonal situations being overlooked and frustration being suppressed, or even situations where employees might retreat or withdraw from the appreciative inquiry process because they are unable to feel included.

A common critique is that appreciative inquiry is too "Pollyannaish", that is excessively optimistic (Fitzgerald, Murrell, and Newman 2001; Grant and Humphries 2006) and that an excessive focus on the positive leaves 
no room for eliminating problems and challenges. Reason (2000) referred to there being a danger in ignoring the shadow process of appreciative inquiry- that is negative aspects within an organization- while others including Pratt (2002) suggest researchers need to"honour the multiple and individual realities of human experience in organizations" (p. 119). Coghlan and colleagues state:

A common criticism of Appreciative Inquiry is that it ignores or even denies problems. While at first blush this view may seem understandable, it is nevertheless untrue. Appreciative Inquiry does address issues and problems, but from a different and often more constructive perspective: it reframes problem statements into a focus on strengths and successes. For example, rather than ask participants to list the problems their organization is facing, they are asked to explain what is going well, why it is going well, and what they want more of in the organization.

(Coghlan, Preskill, and Tzavaras Catsambas 2003, 6)

Rogers and Fraser (2003) follow this line of thought by adding caution in relation to the power and control held by individuals in organizations:

Appreciative Inquiry is based on the heliotropic principle: that people and organizations move toward those things that give them energy and life. Just as plants can grow lopsided as they reach for the light, there is a risk of distortion in what Appreciative Inquiry evaluations focus on and the activities they encourage. By seeking as explicitly for positive features as Appreciative Inquiry does, it runs the very real risk of papering over substantive problems and in fact colluding with the powerful people who want the unexamined to remain so.

(Rogers and Fraser 2003,77$)$

There are few evaluations of appreciative inquiry as a research method and no real indication of why this is the case (Grant and Humphries 2006; Ridley-Duff and Duncan 2015; Grant 2006; 2007). Grant and Humphries (2006) provide a critical evaluation of appreciative inquiry, and (despite the supposed paradox) they found that critical theory and appreciative inquiry could contribute to developing new research and practitioner activities. Essentially there is a call for balance between critical and appreciative elements of inquiry. For example, a Critical Appreciative Process (CAP) strengthens the connection between critical theory and appreciative inquiry by focusing on the emancipatory ideas of each (Grant and Humphries 2006). Nevertheless there are a number of adaptable features with an appreciative inquiry that allow the inquirer to take note of critical elements, which has been identified through integrating CAP in the advancement of appreciative inquiry as a research practice (Ridley-Duff and Duncan 2015).

These critiques and criticisms are understandable given that the appreciative inquiry approach involves a change of mindset and fundamentally trusting a process that is still evolving. However reported successes in using the process through both consulting and through research fieldwork have delivered an overall positive experience of its deployment. For the advancement of appreciative inquiry this robust debate will predictably temper concerns that the approach is too"Pollyannaish".

\section{Appreciative Inquiry in Entrepreneurship Research}

The idea that meaning can be constructed in a positive way led to the application of appreciative protocols in academic research. Apart from Ernesto Poza's work (e. g. Poza, Johnson, and Alfred 1998; Poza and Messer 2001; Poza 2010), there are few examples of an appreciative inquiry approach in a family business setting and to our knowledge none in entrepreneurship research.

\section{Rationale for Pursuing an Appreciative Inquiry approach}

Having established that appreciative inquiry is utilized generally in organizational research, we now focus on how appreciative inquiry could be utilized in an entrepreneurial family business setting. As noted, appreciative inquiry research has been directed toward large organizations and typically non-family businesses, for example, in the health and education sectors (e. g. Reed et al. 2002; Richer, Ritchie, and Marchionni 2009; Grant and Humphries 2006). We depart from this norm by pursuing what works well in entrepreneurial family businesses. 
We viewed appreciative inquiry as a way to reduce the gap between theory and practice deviating slightly away from appreciative inquiry as a tool for organization development and action research. For us to utilize appreciative inquiry in an academic environment we needed to weigh up the arguments for and against engaging the approach for field research and to what extent we adopt the features and evolving adaptations since its inception (Reed 2007). One contentious point was whether appreciative inquiry was"critical" and able to"problematize" an issue or challenge, which was, and still is, a steadfast concern of scholars. We took our lead from the growing body of knowledge confirming the adoption of the appreciative inquiry approach-and variations of it- acknowledging the concept has reached a point where it is able to be adapted to suit different situations. Drawing on the underpinning foundations outlined by Cooperrider and colleagues (2008): "We have reached the end of traditional problem solving. Appreciative Inquiry is a powerful approach to transformation as a mode of inquiry capable of inspiring, mobilizing, and sustaining human system change" (p. 2).

In the current study we chose to adopt this mindset guided by definitions of appreciative inquiry which lean both toward an academic and practice-orientation. First, an academic definition for appreciative inquiry is:

... an organization development process and approach to change management that grows out of the social constructionist thought and its applications to management and organizational transformation. Through its deliberately positive assumptions about people, organizations and relationships, Appreciative Inquiry leaves behind deficit-oriented approaches to management and vitally transforms the ways to approach questions of organizational improvement and effectiveness.

(Cooperrider, Whitney, and Stavros 2008 , 2)

A practical definition refers to appreciative inquiry as:

... the cooperative co-evolutionary search for the best in people, their organizations, and the world around them. It involves the discovery of what gives'life' to a living system when it is most effective, alive, and constructively capable in economic, ecological, and human terms. Appreciative Inquiry involves the art and practice of asking questions that strengthen a systems capacity to apprehend, anticipate, and heighten positive potential.

(Cooperrider, Whitney, and Stavros 2008 , 3)

The integration of academic and practice elements is a powerful and attractive feature of appreciative inquiry. From our study we found that applying appreciative principles was both academically rigorous and practical. Interview participants were very responsive to the format and appeared to open up given they were not being asked about issues and challenges. Although the intention of the study was to seek what works well in each organization, we observed that there was potential for stepping outside the academic mindset to provide consultation and advice about situations that were discussed.

\section{Implementing Appreciative Inquiry Protocols}

So far, we have established the wider relevance of appreciative inquiry to organizations. However, the question of why appreciative inquiry might be useful in entrepreneurship research particularly in the family business context is worthy of further investigation. Most family business research seeks to address problems, issues, and challenges which is not surprising given critical research is important in scholarship. However we rarely investigate what works well in family businesses and it would seem, given the critique and adaptability of appreciative inquiry, that there is a foundation from which to launch a timely investigation. We also know that appreciative inquiry has been utilized and evaluated for field research so we are not alone in pursuing appreciative inquiry as a research approach (e. g. Stowell 2013; Michael 2005; Robinson et al. 2013; Raymond and Hall 2008).

The appreciative approach was used as a research instrument for collecting data through interviews in the field. The study used appreciative protocols when interviewing 27 family members and non-family member employees from three family businesses in the wine industry. The interviews were carried out over a threemonth period. Initially, before the appreciative protocol was applied, interview questions were procured for an investigation into entrepreneurship in family businesses. Once the scope of the questions was confirmed, the form of appreciative wording was addressed.

In designing the questionnaire itself, there was congruence between appreciative questioning and understanding the characteristics of entrepreneurship in the family business, including the vision, guiding principles, 
and peak experiences and high points through the history of the organization. Importantly there was congruence between the appreciative approach and the research question"In what ways can an entrepreneurial family business be sustained across generations?" For guidance on the tone and structure of interview questions, we referred to the appreciative inquiry handbook (Cooperrider, Whitney, and Stavros 2008). The handbook was designed for organization development consultative practice so some adaptation was required. For instance, the handbook presented the "Appreciative Inquiry 4D cycle",4which represented the process where an"affirmative topic" is chosen (Cooperrider, Whitney, and Stavros 2008 , 5). In our study, the appreciative inquiry 4D cycle process was reflected in the interview questions. This model was used conceptually rather than practically, for example, questions aligned with the "discovery" and"dream" phases of the cycle, however the"design" and "destiny" phases related to the implementation of changes, which were outside the scope of the study. The discovery phase related to questions intended for uncovering and learning about what presently exists. For example, respondents would be asked what their peak experiences or high points were, and what gave life to the organization, or to describe the strengths in its operation (e. g. "What do you think works well about family ownership in your business?"). The focus on the dream phase was on the future of the organization and questions would relate to the vision for the continuity of the business. For example, questions such as"What do you believe are the guiding principles/distinguishing values of the organization?" or"Describe the greatest opportunity facing your business" were asked (Cooperrider, Whitney, and Stavros 2008). Neutral questions included "How was your business founded..." or inquiring about the senior generation"stepping back" or the next generation"stepping up". These were carefully worded to stay true to the appreciative motivation of the study (refer Table 3).

Table 3: Interview questions for appreciative inquiry fieldwork.

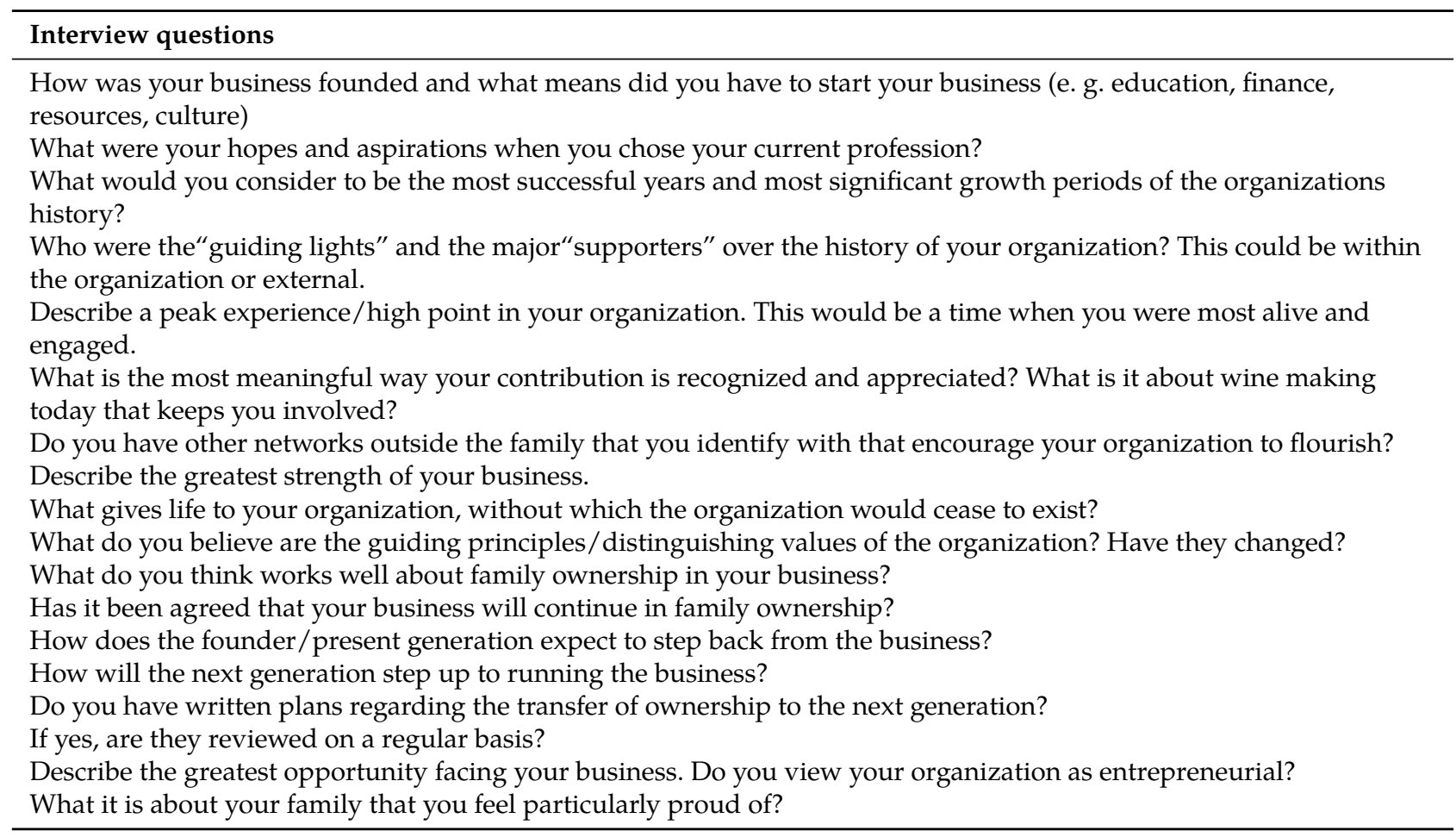

The original study where the interview questions were designed and utilized was in Woodfield (2012). The questionnaire underpinned subsequent journal articles, for example, investigating how family winegrowing businesses could be sustained across generations (Woodfield, Shepherd, and Woods, forthcoming), which is referred to in this article.

Data analysis involved an adaptation of established naturalistic inquiry procedures while adhering to the appreciative inquiry approach (Reed 2007; Cooperrider, Whitney, and Stavros 2008; Denzin and Lincoln 2011). The adaptation included a dual phase analysis (Wiles, Crow, and Pain 2011)- the first phase being data management and coding utilizing NVivo, while the second phase employed further reduction and synthesizing of data utilizing Microsoft Excel. The way data were managed, reduced, and synthesized reflected the interview questions focusing on generative strengths, successes, and vision for the future. The sheer volume of data produced meant it was increasingly important to maintain a"chain of evidence" to increase reliability through the analysis stages (Yin 2009 ,122). As such, the findings- both within case and across cases-reflected what worked well in each of the organizations investigated. 
By way of example, emerging data allowed the researcher to derive a data structure of open concepts, themes, and theoretical dimensions. One dimension that emerged was"entrepreneurial characteristics" of family businesses (Figure 2).

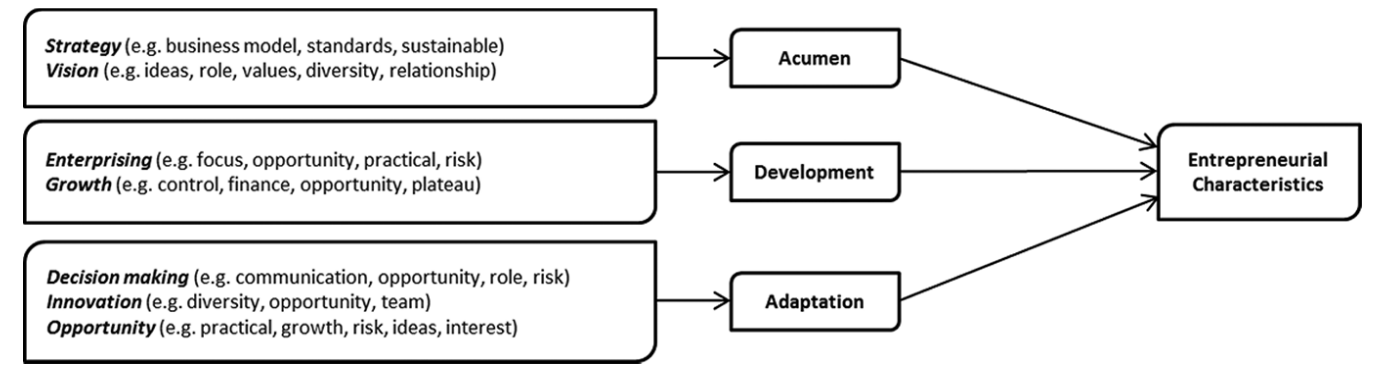

Figure 2: Example of entrepreneurial characteristics data structure (Woodfield 2012 , forthcoming).

The underlying tone of the qualitative data was positive and reflected what worked well on the family business (as displayed in Table 4).

Table 4: Entrepreneurial characteristics themes and representative data.

\begin{tabular}{|c|c|c|}
\hline Second-order themes & First-order themes & Representative data \\
\hline \multicolumn{3}{|c|}{ Overarching dimension: Entrepreneurial Characteristics } \\
\hline 1. Acumen & A. Strategy & $\begin{array}{l}\text { J1. "I wanted to bring a-some of the } \\
\text { good stuff of the corporate, [into] what } \\
\text { was quite a loosely run business, so a lot } \\
\text { more systems and measurements and } \\
\text { responsibility into the business" } \\
\text { (Morgan Merlot) } \\
\text { J2. " ... so that's probably the greatest } \\
\text { issue to restructure things so there's no } \\
\text { pressures and that's very uppermost at } \\
\text { the moment" (Roger Riesling) } \\
\text { J3. "... and where we are wanting to } \\
\text { position ourselves in the market } \\
\text { domestically and internationally" } \\
\text { (Rania Riesling) }\end{array}$ \\
\hline & B. Vision & $\begin{array}{l}\text { K1. "Murray and I, you know, you are } \\
\text { looking at the bigger picture" (Melvin } \\
\text { Merlot) } \\
\text { K2. "Solomon and Simon are the major } \\
\text { visionaries and focus people and the other } \\
\text { three are the ones that help it all go } \\
\text { along" (Nicole) } \\
\text { K3." ... still having the vision and } \\
\text { hoping that everyone else is sharing your } \\
\text { vision" (Roger Riesling) }\end{array}$ \\
\hline \multirow[t]{2}{*}{ 2. Development } & C. Enterprising & $\begin{array}{l}\text { L1. "... their ability to keep moving } \\
\text { forward and to be proactive rather than } \\
\text { reactive" (Todd) } \\
\text { L2. "The other interesting thing was that } \\
\text { because we really searched out varieties } \\
\text { and did a lot of trial work" (Sylvia } \\
\text { sauvignon) } \\
\text { L3. "I'd build a multi-million dollar } \\
\text { company. I'd make all my siblings } \\
\text { jealous" (Renée Riesling) }\end{array}$ \\
\hline & D. Growth & $\begin{array}{l}\text { M1. "[We] grow assets, own assets, } \\
\text { freehold assets, be asset-rich and have a } \\
\text { gross profit objective not a ROI" } \\
\text { (Morgan Merlot) }\end{array}$ \\
\hline
\end{tabular}


3. Adaptation

F.Innovation

G. Opportunity
M2. "And I guess going forward [as] the business hopefully grows or it changes with time, [we] can sort of go into every aspect of the business you want to" (Simon Sauvignon)

M3. "We're probably getting to that point now where we'll have sustained growth" (Roger Riesling)

N1. "Like we need to buy another vineyard, go down and find one, do it, yeah it's a lot of money [but the family can] make quick decisions" (Trevor) N2. "It would be easy to ring someone [and] say 'we want a 150,000 litre tank and it's got to hold wine,' and they'll make it [and] you pay a $\$ 100,000$. [Dad does] the maths and reckons we can get these tanks [built] out here for less than $\$ 50,000$ [each] so Dad says 'we'll build the four tanks, we'll save $\$ 200,000$ and we can buy a Land Cruiser each. Easy" (Simon Sauvignon)

N3. "We can do whatever we want to do. We do from go to whoa. We don't have to wait or call on anybody" (Roger Riesling)

O1. "When I took over from my father and I started bringing in new techniques, like I started bringing in yeast cultures, cold fermentations, stainless steel, things like that, we were getting these quantum leaps in quality" (Murray Merlot) O2. "But then [Solomon] - he's quite innovative in the vineyard as well" (Stella Sauvignon) O3. "So I convinced Dad to give me four hectares to turn into organics" (Renée Riesling)

P1. "They are kind of like loopholes in the general landscape of business. You can jump in this loophole and piss off all your competitors" (Morgan Merlot)

P2. "I really enjoy the stamina of trying

to find the opportunities" (Simon

Sauvignon)

P3. "We are always looking at

opportunities" (Roger Riesling)

In addition, what emerged were the kinds of roles entrepreneurship played in the family businesses. Across the three family businesses investigated there were examples of the families engaging in similar activity to that found in corporate entrepreneurship (Dess et al. 2003; Phan et al. 2009). For example, providing seed capital for ventures (e. g. the next generation starting a brewery while retaining the role of winemaker); strategic renewal through incremental innovation (e.g. introduction of new growing methods, production techniques, processes, and equipment which allowed experimentation with the quality of wine); and a number of innovative partnerships through marketing, production, or purchasing land or wineries. These empirically derived examples lead to a hierarchy of terminology for family entrepreneurship (Figure 3). 


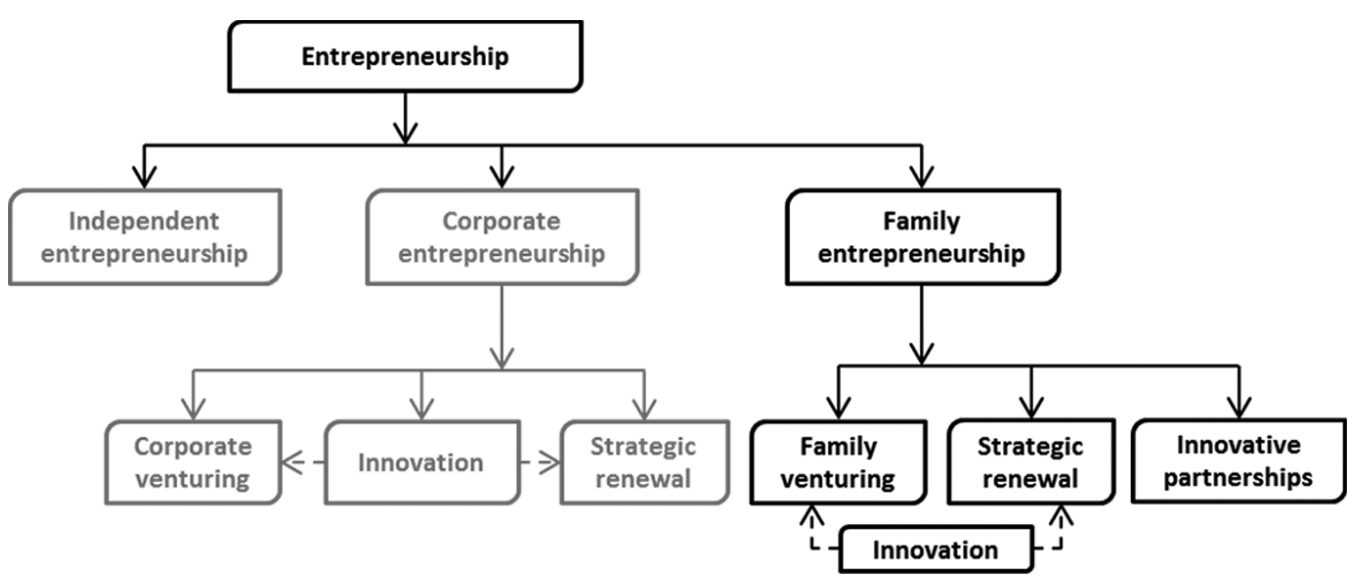

Figure 3: Hierarchy of terminology in family entrepreneurship (Adapted from Sharma and Chrisman 1999, 20).

This portrayal of how the appreciative inquiry protocols were implemented, and the way data were ordered and extrapolated, are displayed more extensively in the original study (Woodfield, 2012).

\section{Advantages and Disadvantages of the Appreciative Inquiry Approach}

The proposal to carry out interviews using the appreciative inquiry approach required the buy in of key family members. Upon approaching firms, the typical pitch from the researcher was that they would like to investigate what works well in the organization and, if pressed, further explanation would be given using the appreciative inquiry lexicon. Without exception, the key contact person was intrigued by the approach. With the understanding that the researcher was investigating what works well in the organization, convincing other family members and employees was straightforward. At each interview, a few disclosures were made. First, the researcher's family ancestry in the wine industry was disclosed. This was not only an ethical decision but proved to be useful as a reference point through the interview as all interviewees were familiar with the researcher's family and their impact on the commercialization of the wine industry. This disclosure guided by the appreciative questions opened up the conversation.

Upon explaining that we were exploring what worked well in the organization, each interviewee lowered their guard and began to speak freely. On occasion data were enriched through unprompted disclosure of problems and issues. Though problems and issues were discussed, they were viewed conversely to understand what works well. It is a common misconception that taking an appreciative inquiry approach means challenges and issues do not arise which was far from the experience in this study. Not incorporating negative experiences that arise can reduce participant engagement, so viewing challenges, problems, and issues within a positive context can promote innovative and creative solutions (Bellinger and Elliott 2011; Grant and Humphries 2006). As such, we received stories of tragedy, challenges, and issues. For example, one employee had ongoing health issues and given an opportunity to discuss this challenge revealed her appreciation of the family's help during this time:

I've had a few health issues and they've just been amazingly supportive throughout it... I probably wouldn't have managed to keep working without it... They've let me take time off when I needed to... Whenever anyone's had any problems or anything, they are so there. And they went down to see somebody's husband who was in hospital. And things like that, just show their support.

(Nicole- employee of Sauvignon Family Estate)

Another example was when a founder was asked what the most meaningful way their contribution would be recognized and appreciated. The answer was led by mentioning challenges around debt:

It's probably one of the hardest things the debt issue... you don't want sort of to leave the family with a monkey so that's probably the greatest issue to restructure things so there's no pressures and that's very uppermost at the moment. And they're part of that, so that the succession thing happens... I guess the other important part of that is ensuring that that's all satisfactorily done so there is no conflict. There's nothing worse than families in conflict, and it happens all the time, especially [with succession]. 
These examples of negative experiences were in fact premised by a negative tone but were actually pragmatic stories that led toward positive outcomes or solutions that support what works well in an entrepreneurial family business.

We found the advantages of the appreciative inquiry approach outweighed the disadvantages. A perceived disadvantage was the temptation to probe interviewees about challenges and issues that were interesting, even if they were irrelevant to finding what works well in the organization. Although care was taken in guiding the interview in an appreciative manner, human nature and the fact people have different personalities and realities meant that deficit orientated data were going to emerge. In such instances the researcher needed to be cognizant of how to approach follow-on questions given the semi-structured interview format.

Perhaps the biggest disadvantage was that the appreciative inquiry process is predominantly a mode for practitioners in the consulting environment and is only emerging as a lens for academic research. This is not to say that the approach is invalid, under researched, or not critically evaluated. However, the relative newness of the approach gives rise to concerns around a paradigm shift not eventuating. Conducting an appreciative inquiry approach is not intended for utopian findings, only as a way to present a different perspective. In the minds of traditional researchers, this change in perspective can be unnerving and bring into question the reliability and validity of data and consequently interpretations, discussions, and conclusions. However our study demonstrated the potential that lies in such an approach for identifying what works well in an entrepreneurial family business. This is especially true when the phenomenon under investigation is conducive to an appreciative focus.

\section{Reflexivity, Appreciative Inquiry, and the Role of the Researcher}

One avenue to appease critics of appreciative inquiry is documenting the researcher's reflexivity in the process. A number of authors have highlighted the importance of reflexivity ${ }^{1}$ in different disciplines (Finlay 2002; Johnson and Cassell 2001; Linsteadl 1994; Malterud 2001; Yin 2011), including management and organization studies (Alvesson 2010; Cunliffe 2003; Hardy, Phillips, and Clegg 2001; Johnson and Duberley 2003; Weick 1999), entrepreneurship studies (Cutcliffe 2003; McKenna 2007), and the family business context (Melin and Nordqvist 2007; Nordqvist, Hall, and Melin 2009). Related to the constructionist perspective, there is a need to reflect on the researcher's influence on the collection and interpretation of data, or as Johnson and Duberley (2003) suggest "to make unexamined meta-theoretical commitments, and remain unaware of their origins, amounts to an abdication of intellectual responsibility which results in poor research practices" (p. 1280). Holland (1999) surmised that reflexivity refers to the task a researcher undertakes through the process of cleaning and sorting data. Given the subjectivity in a qualitative approach, the researcher needs to take a step back at different intervals to reflect upon personal bias and worldviews. This was described by Willig (2001) as"personal reflexivity" involving reflection on the ways the researcher's"... values, experiences, interests, beliefs, political commitments, wider aims in life and social identities [shape] research" (p. 10). As is the case in most research, personal bias can enter the interpretive process, ${ }^{2}$ and as outlined earlier the researcher disclosed his family ancestry in the wine industry. This translated into an advantage where mutual respect was gained and the researcher's openness provided a level of comfort to interviewees. Coupled with the appreciative inquiry approach, this disclosure meant interviews became conversational with guidance from the interview questions. The researcher took care through the highly iterative collection and interpretation process by reflecting on his role in the research process. Ultimately reflexivity promotes credibility, authenticity, and trustworthiness or as Tracy (2010) asserted"... researcher reflexivity... serves as an important means toward sincerity for research in a number of paradigms" (Tracy 2010,849$)$.

\section{Conclusions and Future Research}

Since the 1980s there has been a surge of interest in the application of an appreciative inquiry. Appreciative inquiry closes the gap between theory and practice with examples of it being used as an evaluation technique, an interview tool, and as a methodology for both qualitative and quantitative research. One question that was raised when considering an appreciative inquiry related to what might have happened if questions were asked about issues and challenges. Would the outcome be different? Would what worked well be found? Possibly a more salient way to explore these queries is to question what past studies would look like if an appreciative inquiry approach had been adopted? This article has been an attempt to illustrate an alternative approach for fieldwork where the object is to identify what works well in an organization. The appreciative inquiry approach is rarely used in entrepreneurship research. However a recent call to embrace a positive organizational lens in family business research (Sharma, De Massis, and Gagne 2014; Ceja-Barba 2014), provided some incentive to 
explore the alignment between entrepreneurship in family businesses and appreciative inquiry. Inherently the questions were on topics already appreciative by nature such as the vision each person had for the future of the business, or their background.

Why does an appreciative approach matter? Employing appreciative inquiry protocols proved to be an advantage when first engaging each firm. Respondents who spoke freely about what they saw as strengths, values, or principles in the business that inspired them (Michael 2005). For the study itself, care was taken in the way data were presented through illustrative case studies and cross case analysis. By committing to a consistent approach, the utility of an appreciative inquiry lens became apparent. To validate whether data (in this case quotes) had an appreciative output, they were coded according to their positive or negative connotations. About $80-90 \%$ of the quotes reflected a positive connotation. Although a relatively rough guide, the study demonstrated the overwhelming inclination toward appreciative answers serving to identify what worked well in the businesses. This further demonstrated that the appreciative inquiry lens is not intended for utopian findings but it did contribute toward presenting a different perspective on questions that could be asked about organizations (Cooperrider and Srivestva 1987). The main disadvantage found was maintaining the appreciative focus with follow-on questions. Challenges and issues were raised as part of the interview process and care was taken to allow these stories to play out. This allowed rich data to emerge which, within a positive context, could promote what works well in the organization.

With the introduction of a new methodology, further testing and experimentation are encouraged. First, this study adopted a positive organizational perspective which has recently been described as "fertile territory" for investigation (Ceja-Barba 2014 , 665). Here, appreciative inquiry was utilized as a protocol for interviewing; however, a more developed integration of the full appreciative inquiry consultation process as developed by Cooperrider and Srivestva (1987) could be utilized. The appreciative inquiry protocols are also amenable to use in other industries, other countries, or to a heterogeneous sample.

The way appreciative inquiry was utilized for field research can translate into providing respondents with a taste of what could be in their organization. Although as field research the objective is not to provide advice, there could be an opportunity for respondent organizations to go through a consultative process when they come to be aware of their"positive core". There is a fine line between gathering data and the notion that these data may be helpful to the firm beyond reporting the findings. It may be that distinguishing between fieldwork and a fully-fledged consultation process may ease the way for one to lead to the other respectively. In other words, an appreciative inquiry field study could be used as a tool much like a psychometric test that gauges whether further use of the appreciative inquiry approach would be advantageous. As such, there is an opportunity to step outside the academic mindset to provide consultation and advice on situations discussed during the course of fieldwork.

As a concept, appreciative inquiry presents opportunities for closing the gap between theory and practice, and a continuation of fieldwork toward advisory services is perhaps an easy sell. On the one hand you could be told your organization has a multitude of problems, issues, or challenges, and on the other hand you could present an environment where the organization gains an understanding of their"positive core". Ultimately, we hope that what may appear as a black box being opened for future research can be critiqued, tested, and implemented within entrepreneurship research. It is even possible that past studies could be reinvigorated with its application.

\section{Notes}

${ }^{1}$ Holland (1999) defined reflexivity as:“... applied to that which turns back upon, or takes account of, itself or a person's self, especially methods that take into consideration the effect of the personality or presence of the researcher on the investigation" (p. 464).

2 “... researchers [need] to self-disclose their assumptions, beliefs, and biases. This is the process whereby researchers report on personal beliefs, values, and biases that may shape their inquiry. It is particularly important for researchers to acknowledge and describe their entering beliefs and biases early in the research process to allow readers to understand their positions, and then to bracket or suspend those researcher biases as the study proceeds.... Researchers might use several options for incorporating this reflexivity into a narrative account. They may create a separate section on the'role of the researcher,' provide an epilogue, use interpretive commentary throughout the discussion of the findings" (Creswell and Miller 2000, 127).

\section{References}

Alvesson, M. 2010. “Self-Doubters, Strugglers, Storytellers, Surfers and Others: Images of Self-Identities in Organization Studies." Human Relations 63 (2): 193-217. doi:10.1177/0018726709350372.

Barrett, F., and R. Fry. 2005. Appreciative Inquiry: A Positive Approach to Cooperative Capacity Building. Chagrin Falls, $\mathrm{OH}$ : Taos Institute Publishing. 
Beckhard, R. 1969. Organization Development: Strategies and Models. Reading, MA: Addison-Wesley Publishing Company.

Bellinger, A., and T. Elliott. 2011. "What Are You Looking At? The Potential of Appreciative Inquiry as a Research Approach for Social Work." British Journal of Social Work 41 (4): 708-725. doi:10.1093/bjsw/bcro65.

Bennis, W.C. 1969. Organization Development: Its Nature, Origins, and Prospects. Reading, MA: Addison-Wesley.

Bushe, G.R. 1999. "Advances in Appreciative Inquiry as an Organization Development Intervention." Organization Development Journal 17 (2): 61-68.

Bushe, G.R. 2011. “Appreciative Inquiry: Theory and Critique.” In The Routledge Companion To Organizational Change., edited by D. Boje, B. Burnes, and ]. Hassard, 87-103. Oxford, England: Routledge.

Bushe, G.R. 2012. "Foundations of Appreciative Inquiry: History, Criticism and Potential." Al Practitioner 14 (1).

Bushe, G.R. 2013. "Generative Process, Generative Outcome: The Transformational Potential of Appreciative Inquiry." In Organizational Cenerativity: The Appreciative Inquiry Summit and a Scholarship of Transformation., edited by D.L. Cooperrider, D.P. Zandee, L.N. Godwin, M. Avital, and B. Boland, 89-113. Bingley, England: Emerald Group.

Cady, S.H., and M.A. Caster. 2000. “A Diet for Action Research: An Integrated Problem and Appreciative Focuses Approach to Organization Development." Organization Development Journal 18 (4): 79-93.

Cameron, K.S., J. Dutton, and R.E. Quinn. 2003. Positive Organizational Scholarship: Foundations of a New Discipline. San Francisco, CA: BerrettKoehler Publishers.

Caza, A., and K. Cameron. 2008. "Positive Organizational Scholarship: What Does It Achieve?." In Handbook of Macro-Organizational Behavior., edited by C.L. Cooper, and S. Clegg, 99-116. New York, NY: Sage.

Ceja-Barba, L. 2014. “Towards a Positive Organizational Study of Family-Owned Businesses: Embracing a Fertile Territory." European Journal of Work and Organizational Psychology 23 (5): 665-668. doi:10.1080/1359432X.2014.908186.

Coghlan, A.T., H. Preskill, and T.T. Catsambas. 2003. “An Overview of Appreciative Inquiry in Evaluation.” New Directions for Evaluation 2003 (100): 5-22. doi:10.1002/ev.96.

Cooperrider, D.L. Appreciative Inquiry: Toward a Methodology for Understanding and Enhancing Organizational Innovation. Ohio: Case Western Reserve University, 1986. PhD Unpublished doctoral dissertation.

Cooperrider, D.L., and M. Avital. 2004. Advances in Appreciative Inquiry: Constructive Discourse and Human Organisation., edited by David L. Cooperrider, and Michel. Avital. Amsterdam, Netherlands: Elsevier 1 vols. Vol. 1.

Cooperrider, D.L., and L.E. Sekerka. 2006. “Toward a Theory of Positive Organizational Change.” In Organization Development: A Jossey-Bass Reader., edited by J.V. Gallos, 223-238. San Francisco, CA: Jossey-Bass.

Cooperrider, D.L., P.F. Sorenson, D. Whitney, and T.F. Yaeger. 2000. Appreciative Inquiry: Rethinking Human Organisation toward a Positive Theory ofChange. Champaign, IL: Stripes Publishing.

Cooperrider, D.L., and S. Srivestva. 1987. "Appreciative Inquiry in Organizational Life." In Research in Organizational Change and Development., edited by R. Woodman, and W. Pasmore, 129-169. Greenwich, CT: JAI Press.

Cooperrider, D.L., D. Whitney, and J.M. Stavros. 2003. Appreciative Inquiry Handbook: The First in a Series of Al Workbooks for Leaders of Change. Bedford Heights: Lakeshore Publishers.

Cooperrider, D.L., D.K. Whitney, and J.M. Stavros. 2008. Appreciative Inquiry Handbook for Leaders of Change., 2nd ed. Brunswick, OH: Crown Custom Publishing.

Creswell, J. W., and D. L. Miller. 2000. “Determining validity in qualitative inquiry.” Theory into Practice 39 (3): 124-130.

Creswell, J.W. 2009. Research Design: Qualitative, Quantitative, and Mixed Methods Approaches., 3rd ed. Thousand Oaks, CA: Sage.

Crotty, M. 1998. The Foundations of Social Research: Meaning and Perspective in the Research Process. St Leonards, NSW, Australia: Allen and Unwin.

Cunliffe, A.L. 2003. “Reflexive Inquiry in Organizational Research: Questions and Possibilities." Human Relations 56 (8): 983-1003. doi:10.1177/00187267030568004.

Cutcliffe, J.R. 2003. “Reconsidering Reflexivity: Introducing the Case for Intellectual Entrepreneurship.” Qualitative Health Research 13 (1): 136-148. doi:10.1177/1049732302239416.

Denzin, N.K., and Y.S. Lincoln. 2011. The Sage Handbook of Qualitative Research., 4th ed. Thousand Oaks, CA: Sage.

Dess, G.G., R. Duane Ireland, S.A. Zahra, S.W. Floyd, J.J. Janney, and P.J. Lane. 2003. “Emerging Issues in Corporate Entrepreneurship." Journal of Management 29 (3): 351-378. doi:10.1016/S0149-2063_03_00015-1.

Dick, B. 2004. "Action Research Literature: Themes and Trends." Action Research 2 (4): 425-444. doi:10.1177/1476750304047985.

Egan, T.M., and C.M. Lancaster. 2005. “Comparing Appreciative Inquiry to Action Research: OD Practitioner Perspectives.” Organization Development Journal 23 (2): 29-49.

Fineman, S. 2006. “On Being Positive: Concerns and Counterpoints.” Academy of Management Review 31 (2): $270-291$. doi:10.5465/AMR.2006.20208680.

Finlay, L. 2002. "Negotiating the Swamp: The Opportunity and Challenge of Reflexivity in Research Practice." Qualitative Research 2 (2): 209-230. doi:10.1177/146879410200200205.

Fitzgerald, S.P., K.L. Murrell, and H.L. Newman. 2001. “Appreciative Inquiry- The New Frontier.” In Organization Development: Data Driven Methods for Change., edited by J. Waclawski, and A.H. Church, 203-221. San Francisco, CA: Jossey-Bass Publishers.

Fitzgerald, S.P., C. Oliver, and J.C. Hoxsey. 2010. “Appreciative Inquiry as a Shadow Process." Journal of Management Inquiry 19 (3): $220-233$. doi:10.1177/1056492609349349.

French, W.L., C.H. Bell, and R.A. Zawacki. 1989. “A History of Organization Development.” In Organization Development: Theory, Practice, and Research., edited by W.L. French, C.H. Bell, and R.A. Zawacki, 18-32. Homewood, IL: BPI Irwin.

Cergen, K.J. 1978. “Toward Cenerative Theory." Journal of Personality and Social Psychology 36 (11): 1344-1360. doi:10.1037/0022-3514.36.11.1344

Colembiewski, R.T. 1998. "Appreciating Appreciative Inquiry: Diagnosis and Perspectives on How to Do Better." In Research in Organizational Change and Development., edited by R.W. Woodman, and W.A. Pasmore, 1-45. Stamford, CT: JAI Press.

Grant, S.L.P. A Paradox in Action? A Critical Analysis of an Appreciative Inquiry., Waikato Management School University of Waikato, 2006. Doctor of Philosophy PhD thesis.

Grant, S.L.P. 2007. “Learning through`Being' and 'Doing'.” Action Research 5 (3): 265-274. doi:10.1177/1476750307081017. 
Crant, S.L.P., and M. Humphries. 2006. “Critical Evaluation of Appreciative Inquiry: Bridging an Apparent Paradox." Action Research 4 (4): 401-418. doi:10.1177/1476750306070103.

Hardy, C., N. Phillips, and S. Clegg. 2001. “Reflexivity in Organization and Management Theory: A Study of the Production of the Research 'Subject'." Human Relations 54 (5): 531-560. doi:10.1177/0018726701545001.

Holland, R. 1999. "Reflexivity." Human Relations 52 (4): 463-484. doi:10.1177/001872679905200403.

Jackson, P.Z., and M. McKergow. 2002. The Solution Focus: Making Coaching and Change SIMPLE. London, England: Nicolas Brealey.

Johnson, P., and C. Cassell. 2001. “Epistemology and Work Psychology: New Agendas." Journal of Occupational and Organizational Psychology 74 (2): 125-143.

Johnson, P., and J. Duberley. 2003. “Reflexivity in Management Research." Journal of Management Studies 40 (5): 1279-1303. doi:10.1111/1467-6486.00380.

Jupp, V. 2006. The Sage Dictionary of Social Research Methods. London, UK: Sage.

Kuratko, D.F. 2005. “The Emergence of Entrepreneurship Education: Development, Trends, and Challenges." Entrepreneurship: Theory Practice 29 (5): 577-597. doi:10.1111/j.1540-6520.2005.00099.x.

Kuratko, D.F., and D.B. Audretsch. 2009. "Strategic Entrepreneurship: Exploring Different Perspectives of an Emerging Concept." Entrepreneurship: Theory Practice 33 (1): 1-17. doi:10.1111/j.1540-6520.2008.00278.x.

Linsteadl, S. 1994. “Objectivity, Reflexivity, and Fiction: Humanity, Inhumanity, and the Science of the Social." Human Relations 47 (11): 1321-1346. doi:10.1177/001872679404701102.

Logan, J. 2016 (April) 12. ““'Appreciative Inquiry.”. AccessedApril12. http://blogs.oregonstate.edu/programevaluation/2015/12/29/appreciative-inquiry/.

Malterud, K. 2001. “Qualitative Research: Standards, Challenges, and Guidelines.” Lancet 358 (9280): 483-488.

Mathie, A., and G. Cunningham. 2003. "From Clients to Citizens: Asset-Based Community Development as a Strategy for Community-Driven Development." Development in Practice 13 (5): 474-486. doi:10.1080/0961452032000125857.

McKenna, S. 2007. “Deconstructing a Personal“Academic"|“Practitioner" Narrative through Self-Reflexivity." Qualitative Research in Organizations and Management: An International Journal 2 (2): 144-160. doi:10.1108/17465640710778539.

McNiff, J. 2013. Action Research: Principles and practice., 3rd ed. New York, NY: Routledge.

Melin, L., and M. Nordqvist. 2007. "The Reflexive Dynamics of Institutionalization: The Case of the Family Business." Strategic Organization 5: 321-333. doi:10.1177/1476127007079959.

Michael, S. 2005. “The Promise of Appreciative Inquiry as an Interview Tool for Field Research.” Development in Practice 15 (2): $222-230$. doi:10.1080/09614520500042094.

Miles, M.B., and A. Michael Huberman. 1994. Qualitative Data Analysis. Thousand Oaks, CA: Sage.

Miller, M.C., S.P. Fitzgerald, K.L. Murrell, J. Preston, and R. Ambekar. 2005. “Appreciative Inquiry in Building a Transcultural Strategic Alliance: The Case of a Biotech Alliance between a U.S. Multinational and an Indian Family Business." The Journal of Applied Behavioral Science 41 (1): 91-110. doi:10.1177/0021886304273060.

Morgan, G. 1980. “Paradigms, Metaphors, and Puzzle Solving in Organization Theory.” Administrative Science Quarterly $24: 605-622$.

Nordqvist, M., A. Hall, and L. Melin. 2009. "Qualitative Research on Family Businesses: The Relevance and Usefulness of the Interpretive Approach." Journal of Management and Organization 15 (3): 294-308.

Phan, P.H., M. Wright, D. Ucbasaran, and W.L. Tan. 2009. "Corporate Entrepreneurship: Current Research and Future Directions." Journal of Business Venturing 24 (3): 197-205. doi:10.1016/j.jbusvent.2009.01.007.

Poza, E.J. 2010. Family Business., 3rd ed. Mason, OH: South Western.

Poza, E.J., S. Johnson, and T. Alfred. 1998. “Changing the Family Business through Action Research." Family Business Review 11 (4): $311-323$. doi:10.1111/j.1741-6248.1998.00311.x.

Poza, E.]., and T. Messer. 2001. "Spousal Leadership and Continuity in the Family Firm." Family Business Review 14 (1): 25-36. doi:10.1111/j.1741-6248.2001.00025.x.

Pratt, C. 2002. "Creating Unity from Competing Integrities: A Case Study in Appreciative Inquiry Methodology." Appreciative Inquiry and Organizational Transformation: Reports from the Field 99-120.

Raymond, E.M., and C. Michael Hall. 2008. "The Potential for Appreciative Inquiry in Tourism Research." Current Issues in Tourism 11 (3): 281-292. doi:10.1080/13683500802140323.

Reason, P. 2000. "Action research as spiritual practice. University of Surrey Learning Community Conference, 4-5 May.". Accessed February 15, 2017. http://www.peterreason.eu/Papers/AR_as_spiritual_practice.pdf.

Reed, J., P. Pearson, B. Douglas, S. Swinburne, and H. Wilding. 2002. “Going Home from Hospital- An Appreciative Inquiry Study." Health and Social Care in the Community 10 (1): 36-45.

Reed, J. 2007. Appreciative Inquiry: Research for Change. Thousand Oaks, CA: Sage.

Richer, M.C., J. Ritchie, and C. Marchionni. 2009. "'If We Can't Do More, Let's Do It Differently!': Using Appreciative Inquiry to Promote Innovative Ideas for Better Health Care Work Environments." Journal of Nursing Management 17 (8): 947-955. doi:10.1111/j.1365-2834.2009.01022.x.

Ridley-Duff, R.J., and G. Duncan. 2015. "What Is Critical Appreciation? Insights from Studying the Critical Turn in an Appreciative Inquiry." Human Relations 68 (10): 1579-1599. doi:10.1177/0018726714561698.

Robinson, G., C. Priede, S. Farrall, J. Shapland, and F. McNeill. 2013. “Doing'Strengths-Based” Research: Appreciative Inquiry in a Probation Setting." Criminology and Criminal Justice 13 (1): 3-20.

Rogers, P.., and D. Fraser. 2003. “Appreciating Appreciative Inquiry.” In Using Appreciative Inquiry in Evaluation., edited by H. Preskill, and A.T. Coghlan, 75-84. San Francisco, CA: Jossey-Bass.

Schein, E.H. 1969. Process Consultation: Its Role in Organization Development. Reading, MA: Addison-Wesley Publishing Company.

Schein, V.E., and L.E. Greiner. 1977. “Can Organization Development Be Fine Tuned to Bureaucracies.” Organizational Dynamics 5 (3): 48-61.

Sharma, P., and J.J. Chrisman. 1999. "Toward a Reconciliation of the Definitional Issues in the Field of Corporate Entrepreneurship." Entrepreneurship: Theory and Practice 23 (3): 11-27. doi:10.1007/3-540-48543-0_4. 
Sharma, P., A. De Massis, and M. Gagne. 2014. “Family Business: A Fertile Ground for Research on Time, Teams and Positive Organizational Study." European Journal of Work and Organizational Psychology 23 (5): 674-679. doi:10.1080/1359432X.2014.900046.

Srivastva, S., and D.L. Cooperrider. 1986. “The Emergence of the Egalitarian Organization.” Human Relations 39 (8): 683-724. doi:10.1177/001872678603900801.

Stavros, J., and C. Torres. 2005. Dynamic Relationships: Unleashing the Power of Appreciative Inquiry in Daily Living. Chagrin Falls, OH: Taos Institute Publishing.

Stowell, F. 2013. "The Appreciative Inquiry Method-A Suitable Candidate for Action Research?" Systems Research and Behavioral Science 30 (1): 15-30. doi:10.1002/sres.2117.

The Center for Appreciative Inquiry. Principles of Appreciative Inquiry. 2016. AccessedApril17. http://www.centerforappreciativeinquiry.net/more-on-ai/principles-of-appreciative-inquiry/.

Tracy, S.J. 2010. “Qualitative Quality: Eight’Big Tent’ Criteria for Excellent Qualitative Research.” Qualitative Inquiry16 (10): $837-851$. doi:10.1177/1077800410383121.

Warner, B.W. 1997. “The New Agenda for Organization Development.” Organizational Dynamics 26 (1): 6-20.

Weick, K.E. 1999. “Theory Construction as Disciplined Reflexivity: Tradeoffs in the 90s." Academy of Management Review 24 (4): $797-806$. doi:10.5465/AMR.1999.2553254.

Whitney, D., and T.-B. Amanda. 2003. The Power of Appreciative Inquiry: A Practical Cuide to Positive Change. San Francisco, CA: Berrett-Koehler.

Wiles, R., G. Crow, and H. Pain. 2011. “Innovation in Qualitative Research Methods: A Narrative Review.” Qualitative Research 11 (5): $587-604$. doi:10.1177/1468794111413227.

Willig, C. 2001. Introducing Qualitative Research in Psychology: Adventures in Theory and Method. Buckingham, England: Open University Press.

Woodfield, P.]. 2012. "Intergenerational Entrepreneurship in Family Business: Conceptualising ways Entrepreneurial Family Businesses can be Sustained across Cenerations." Doctor of Philosophy, Management and International Business, The University of Auckland.

Yaeger, T.F., P.F. Sorensen, and U. Bengtsson. 2005. "Assessment of the State of Appreciative Inquiry: Past, Present, and Future." Research in Organizational Change and Development 15: 297-319. doi:10.1016/S0897-3016(04)15009-X.

Yin, R.K. 2009. Case Study Research: Design and Methods., 4th ed. Los Angeles, CA: Sage.

Yin, R.K. 2011. Qualitative Research from Start to Finish. New York, NY: Guilford Press. 